\title{
Legisladores Representantes Empresariales en Argentina y Brasil: la emergencia de una categoría de especialistas
}

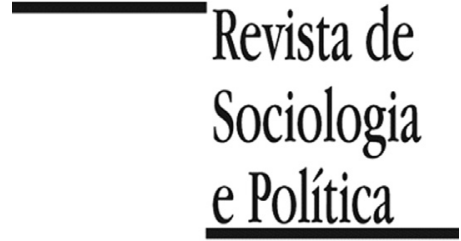

DOI 10.1590/1678-987317256306

\author{
Luis Miguel Donatello
}

\begin{abstract}
Resumen
Este trabajo se propone describir algunas características sociológicas de aquellos representantes corporativos empresariales que han sido legisladores en Brasil y Argentina en la última década. Para ello se trabajó con las bases de datos disponibles del proyecto Élites Parlamentarias-PELA de la Universidad de Salamanca, construía bajo la dirección de Manuel Alcántara. Al mismo tiempo, se triangulo dicha información con fuentes cualitativas. Los resultados nos hablan de la emergencia de una categoría de especialistas en la representación de intereses empresariales que han emergido a partir de las oportunidades que la democracia abrió en ambos países. En ese sentido, la dimensión política parece adquirir más preeminencia que los rasgos sociológicos de los agentes seleccionados. Ello nos permitirá dialogar con algunas teorías que sostienen la existencia de una nueva política asociada a tendencias globales.
\end{abstract}

PALABRAS CLAVE: legisladores; representantes empresariales; Argentina; Brasil; democracia.

Recebido em 12 de Junio de 2016. Aceito em 4 de Noviembre de 2016.

\section{Presentación del problema ${ }^{1}$}

\footnotetext{
1 Esta investigación fue posible gracias al apoyo económico de la Corporación Andina financiera-CAF, quien financió mí estadía de investigación en el Instituto de Iberoamérica de la Universidad de Salamanca durante los meses de mayo y junio de 2015. Agradecemos las sugerencias y comentarios de los dictaminadores anónimos de la Revista de Sociologia e Política.

${ }^{2}$ Los términos corporación o empresario se pueden prestar a confusiones. Por ende, vale la pena aclarar que a los fines empíricos, se toma como referencia a legisladores que son miembros de cámaras empresariales de diferentes grados, o bien de organizaciones patronales. Quedan excluidos, por ende, los representantes de sindicatos de trabajadores.
}

$\mathrm{E}$ ste trabajo se propone describir algunas características sociológicas de aquellos representantes corporativos empresariales que han sido legisladores en Brasil y Argentina en la última década. Dicho fenómeno supone, al menos, el cruce de tres problemáticas ${ }^{2}$. La primera de ellas se vincula a las características que asume la actividad política en un contexto de trasformaciones societales globales. Por ende, nos conduce a discutir el mentado problema de la crisis de representación asociada a dichas tendencias en lo atinente al mundo económico. El segundo tópico que trataremos se liga con una problemática que viene ganando terreno en las ciencias sociales argentinas en particular y latinoamericanas en general: los mecanismos de profesionalización política. En ese sentido, un error epistemológico aparece recurrentemente en los estudios sobre profesionalización: pensar que hay un solo modelo. Con lo cual, estudiar a legisladores que han sido o son representantes empresariales nos puede ilustrar sobre algunas características ligadas a distintos caminos de acceso a la profesión política. Finalmente, este estudio se liga con una corriente cuya importancia no podemos soslayar: la aparición creciente en la actividad política de personas que han construido su prestigio por fuera de ella. De allí que conocer la cantidad de personas que ingresan a la política desde el mundo empresarial también nos puede ayudar en ese sentido.

Para ello, propongo concentrarnos realizar un ejercicio comparativo entre Argentina y Brasil. El mismo, se justifica por varios motivos. Ambos países nacieron como estados nacionales incorporados al mercado mundial como exportadores de materias primas. Por ende, su trasnacionalización ha sido temprana, al mismo tiempo que periférica. Luego, han sufrido procesos polí- 
${ }^{3}$ Vale la pena mencionar que estos hallazgos previos, son solidarios con la hipótesis desarrollada por Costa, Costa y Nunes (2014).

${ }^{4}$ Por una cuestión estética y a los fines de economía terminológica, en adelante los llamaré Legisladores Representantes Empresariales-LRE. ticos y económicos coetáneos. También forman parte de una misma realidad regional. Sin embargo, sus estructuras sociales y sus sistemas políticos son bien diferentes. De allí que son dos casos aptos para ver las respuestas disímiles frente lógicas globales. Es decir, nos brindan elementos para ver cómo morfologías sociales y formas institucionales distintas afrontan problemas comunes.

Es menester aclarar que la indagación sobre la que se asienta este artículo se funda en una serie de indagaciones previas (Donatello 2013; 2014). Las mismas se centraron en el vínculo entre élites empresariales y políticas en Brasil y Argentina. El universo sobre el cual me concentré estuvo compuesto por las principales centrales patronales de ambos países: la Confederação Nacional da Indústria-CNI y la Unión Industrial Argentina-UIA.

En dicha indagación, se tomaron en cuenta estas organizaciones y no las vinculadas al sector agropecuario por dos razones. En el caso de Brasil, porque la CNI - a partir del incentivo del Estado - se fue erigiendo en la organización que fue monopolizando la representación sectorial. En el caso argentino porque en los últimos treinta años la Sociedad Rural Argentina-SRA, fue diluyendo su capacidad de representar a los sectores terratenientes. Asimismo, la aparición del agrobusiness como actividad económica hegemónica, condujo a que la UIA apareciera como instancia más apta tales fines. Ello queda de relieve a partir del peso del sector alimenticio en dicha institución. Al mismo tiempo, existe un inconveniente a la hora de volver comparable las respuestas en torno a la ocupación, en lo relativo al sector agropecuario. Ello se debe a la heterogeneidad de la propiedad rural dentro de cada país y al grado de subjetividad en las respuestas al respecto: en ese sentido, es muy difícil encontrar personas que respondan "terrateniente" como principal ocupación previa al ingreso a la cámara baja. En síntesis, en términos de Costa (2014) se trata de una comparación entre élites empresariales, más que entre élites económicas

De este modo, reconstruyendo las trayectorias de sus miembros, se arribó a una hipótesis: en Brasil, a diferencia de Argentina, existen mecanismos normativos y prácticas más fluidas que posibilitan la interacción entre élites económicas y políticas tanto en el poder ejecutivo, como en el poder legislativo. Ello se debe a que en Brasil nos encontramos con redes domésticas que unen a la dirigencia económica con la política y otros tipos de posiciones de liderazgo ${ }^{3}$; mientras que en Argentina podemos ver una temprana diferenciación entre las diferentes esferas de producción social. Ello nos habla de un capitalismo más diversificado, pero con una base social más homogénea "por arriba" en Brasil y de una situación inversa en Argentina.

Teniendo en cuenta estas problemáticas y en función de los antecedentes planteados, en este artículo se propone la siguiente tarea: explorar las Cámaras de Diputados de ambos países a los efectos de discutir con la hipótesis mencionada. Los interrogantes que guiarán la indagación serán: A partir del estudio de las trayectorias de los Diputados que han sido también representantes empresariales (LRE) ${ }^{4}$ de Brasil y Argentina, ¿son válidos los argumentos emergentes de los trabajos mencionados? Realizando el mismo ejercicio, ¿qué podemos inferir sobre la actividad política en nuestro mundo globalizado? ¿Existe una modalidad específica de representación de los intereses económicos concentrados en el parlamento? ¿Se puede hablar de circulación en dicho ámbito?

Para ello responder los interrogantes y discutir las hipótesis previas, se trabajará con la base de datos del proyecto Elites Parlamentarias de América Latina-PELA, asentado en la Universidad de Salamanca (Alcántara Saéz 2015). Antes de continuar, es importante describir los principales antecedentes del problema. 


\section{Las dimensiones de los intereses económicos en la vida política}

${ }^{5}$ Una esfera de la vida social que nos ofrece ejemplos singulares de esta tendencia está constituida por las representaciones y prácticas religiosas. Allí se manifiestan fenómenos de yuxtaposiciones y emergencias de fenómenos contradictorios como nuevos tradicionalismos (Hervieu-Leger 1993).
${ }^{6}$ Como veremos al final, esto se toca también con el ya clásico problema de investigación en torno al neocorporativismo.
Como he mencionado antes, el tema de este artículo supone el cruce de tres problemáticas. El primero de ellos está asociado al impacto del proceso de globalización en la vida política. En ese sentido, es imposible pensar las transformaciones sociales más recientes sin hacer referencia a un proceso mucho más largo. Me refiero a aquello que - al menos en el contexto europeo occidental - podemos denominar como proceso de individuación o individualización. Ello no quiere decir que las personas se vuelvan más individualistas o egoístas. Por el contrario, esta tendencia se identifica con una manera en la que los humanos construimos nuestra propia identidad, proyectos y estilos de vida de un modo cada vez más escindido de referencias exteriores (Martuccelli 2010; Zabludovsk y Kuper 2013).

Este desarrollo es concomitante y se ha visto reforzado con otro aspecto que los especialistas denominan ampliación de la agencia. De manera análoga a la tendencia anterior, ello no significa que cada quien tenga más capacidad de control o de decisión sobre el curso de su vida. Sino que - fruto de transformaciones estructurales - se disuelven los constreñimientos exteriores que puede tener la acción humana. Y, por ende, sus límites se expanden en escenarios caracterizados por la incertidumbre y la contingencia (Bauman 1999).

Finalmente, estos términos son inseparables de otro orden de fenómenos que se asociación al concepto destradicionalización. Nuevamente, no debe interpretarse esta palabra como una simple desaparición de formas de vida tradicionales. Sino que, al disolverse las pautas institucionales que dotaron de sentido a buena parte de las poblaciones occidentales durante el siglo XX, mucha gente se aferra a lo que puede para poder construir certezas (Giddens $1994)^{5}$.

De acuerdo con este diagnóstico, los mecanismos tradicionales de representación política se vienen corroyendo. Lo cual redunda, a su vez, en una significativa crisis de representatividad de los partidos políticos y en el surgimiento de liderazgos por fuera de ellos (Crouch 2004). Este argumento se puede matizar a partir de distintas evidencias. De hecho, dados los marcos legales existentes en buena parte del mundo, los partidos políticos siguen siendo la forma más extendida de mediación entre representantes y representados. Asimismo, la propia complejidad de la vida colectiva hace que la lógica especialización política siga expandiéndose.

Individuación, ampliación de la agencia, destradicionalización y crisis de representación, son todos temas que nos conducen hacia el siguiente interrogante: ¿En qué medida personas que ocupan posiciones de liderazgo en el terreno económico pasan a convertirse en referentes políticos? Al estudiar este fenómeno en el terreno parlamentario, podemos evaluar la pertinencia de los argumentos mencionados en un terreno más denso y menos visible. Resulta relativamente simple reforzar los argumentos expuestos a partir de lo que sucede en el poder ejecutivo. En buena parte de la historia reciente, podemos mencionar a figuras que resaltan por haber surgido de otros espacios que no han sido los partidos políticos. Por el contrario, yendo a la arena legislativa, pueden establecerse regularidades y excepciones. En torno a esta cuestión es que estableceremos uno de los ejes de nuestra indagación ${ }^{6}$.

El segundo eje se encuentra ligado a los mecanismos que, en la actualidad, configuran la profesionalización de la actividad política. Esta es una cuestión clásica de las ciencias sociales (Weber 1984; Michels 2008). Ahora bien, ello no significa que las categorías con las cuáles se pensó este fenómeno sean necesariamente útiles hoy en día. En ese sentido, existen varios desarrollos. 
Uno, autoevidente, consiste en estudiar comparativamente carreras y, de ahí, suponer que el ingreso al parlamento (o a otra instancia de los poderes del Estado) es una vía de profesionalización. Con lo cual, el desafío propuesto por dicha perspectiva consiste en ver cuáles son los caminos hacia la profesionalización. Sin embargo, esta alternativa nos dice poco sobre lo que puede ocurrir luego con los políticos profesionales: es decir, las estrategias de salida. Para ello es significativo mencionar la propuesta metodológica encarada por Alcántara Saéz (2012) en su estudio sobre la profesión política.

Otra, implica suponer que existe un campo político. Ello nos conduciría a establecer cuáles son sus límites objetivos, cómo se adquiere su capital específico - el reconocimiento - y las maneras a partir de las cuáles se establece la distinción entre especialistas (profesionales) y legos. Así como también las reglas que constituyen la ortodoxia y la heterodoxia en cuanto a las carreras y la adquisición del capital político (Gaxie 2004; Offerle 2004). El obstáculo de este enfoque es que supone que tiende a una visión teleológica, en función de la cual todo sistema político debe entenderse a partir de un modelo teórico.

Sin embargo, dentro de este tópico, nos encontramos con una propuesta que pone énfasis en la reconversión (Tissot, Gauber \& Lechien 2004). Son muy comunes los trabajos que - en esta línea - han estudiado cómo dirigentes políticos o sindicales se han transformado en cuadros gerenciales dentro del mundo empresarial. Esta perspectiva es, por ende, sumamente útil para el fenómeno que nos interesa abordar.

Por último, existe una tercera corriente estrechamente vinculada con la anterior y que podemos ligar a nuestro objeto: la constituyen los estudios sobre aquellos que llegan al parlamento desde afuera de la vida política. Ello ha implicado la utilización de una serie de términos como outsider, disidente, amateur, paracaidista, arribista, recién llegado, converso, etcétera. Todas estas caracterizaciones, en un sentido, poseen una valoración negativa para los que viene de afuera de la política. Pero, ello no implica necesariamente una traducción en la calidad política (Alcántara Saéz 2013).

Vale la pena señalar que, para el caso de la cámara alta en Brasil, existe un sólido trabajo análogo al que aquí se presenta (Cf. Costa, Costa \& Nunes 2014). En dicha investigación emergen conclusiones sumamente significativas: a) que en el caso de los representantes empresariales, el capital económico reemplaza al saber profesional; $b$ ) que las carreras entre los distintos status socio-profesionales previos, tienden a homogeneizarse (a diferencia de lo que ocurriría en el parlamento, donde las trayectorias de los LRE son más cortas), y $c$ ) el ingreso al Senado, constituye una manera de adquirir prestigio y estabilidad en términos de una carrera de representación de intereses.

De acuerdo a lo expuesto, esta indagación se propone contribuir a esta descripción, tratando de ver en qué medida los LRE en la Cámara Baja constituyen algo fuera de lo común o no. De este modo, los interrogantes planteados, nos sirven para destacar la importancia del fenómeno que propongo abordar.

\section{Características metodológicas del estudio}

${ }^{7}$ Las características metodológicas sobre la fuente de este estudio pueden consultarse en Élites (2015).
A los fines de este trabajo hemos utilizado tres bases de datos disponibles para Argentina, comprendiendo todos los períodos legislativos que van desde 2003 a 2013; y las dos bases de Brasil, las cuales van de 2002 a $2011^{7}$.

En todos los casos se ha procedido con muestras representativas, con un nivel de confianza del 95,5\% para cada estudio y con distintos errores de amuestra según la fuerza política. La recolección se realizó mediante entrevistas 
personales realizadas por el equipo mencionado (Alcántara Saéz 2015). De este modo, se recortó un universo en función de las categorías ocupacionales mencionadas, reagrupándolas, para luego realizar la descripción que expondremos a continuación.

Asimismo, los datos fueron triangulados a través de otro procedimiento: se revisaron para cada período las listas de legisladores. En el caso argentino, dada la escasez de información parlamentaria, se cotejaron los nombres de los legisladores, con los de los miembros de las principales cámaras patronales en el lapso temporal de referencia: la UIA, la Cámara Argentina de Comercio-CAC y la Sociedad Rural Argentina-SRA y de las principales instancias provinciales y sectoriales. En Brasil, donde la información parlamentaria es más voluminosa, se estudiaron los Curriculum Vitae de los diputados con los mismos criterios.

Vale la pena aclarar que, para las bases de datos del PELA, se tuvieron en cuenta las preguntas relativas a la profesión previa de los legisladores, del mismo modo en que también se contemplaron aquellas ligadas a sus actividades políticas anteriores al acceso a la legislatura. De este modo, se agruparon las categorías comerciante, empresario/industrial y cargo ejecutivo en empresas: sí bien los términos mencionados son relativamente ambiguos, ello no constituye un obstáculo. Lo cual se debe a que, a partir de la triangulación con las otras fuentes que se reconstruyeron, se pudo establecer que efectivamente podían tener un pasado en dichas actividades había estado ligado a alguna instancia de representación sectorial. Es decir, los legisladores agrupados podían no estar en una central patronal nacional, pero sí en alguna asociación regional o sectorial. $\mathrm{Y}$, si bien información brindada por el proyecto de referencia es únicamente estadística, la indagación cualitativa permitió darle validez al agrupamiento categorial.

Asimismo, está claro que no se puede realizar una comparación exacta dado que disponemos de tres bases para un caso y dos para el otro. Sin embargo, esto tampoco constituye un obstáculo. En primer lugar, porque el trabajo del equipo de referencia constituye el instrumento más sistemático que disponemos. En ese sentido, vale la pena resaltar que los datos ya poseen una elaboración comparativa extensa que ha permitido refinar las potencialidades del instrumento. En segundo lugar, porque a pesar de la disparidad en la información, la misma nos puede brindar indicios para realizar el ejercicio comparativo. Y, en tercer lugar, porque el ejercicio cualitativo que se realizó nos permitió reforzar la validez de la fuente y ver que hay regularidades para ambos casos que arrojan resultados análogos. Y, en cuarto lugar, porque se sintetiza información para un marco temporal más o menos homogéneo: la última década.

Es menester señalar que - con fines retóricos - se han ponderado las bases y se trabajará en la exposición con porcentajes: dado que se trata de un ejercicio descriptivo y no de estadística inferencial, ello no implica obstáculos metodológicos. Realizadas estas aclaraciones podemos pasar a trabajar con la información obtenida.

\section{Los Legisladores Representantes Empresariales (LRE) en Brasil y Argentina}

A los fines de establecer la morfología del fenómeno que nos ocupa, hemos escogido partir de los porcentajes de LRE en ambos países. Ello nos muestra elementos que - desde el inicio - nos permiten confrontar los argumentos expuestos al principio. Fundamentalmente, el argumento de una mayor y más organizada representación sectorial en el caso brasileño. Si vamos a los datos empíricos, vemos una realidad más compleja (Cuadro 1):

La lectura del cuadro anterior nos muestra que, en ambos países, las cifras se han ido acercando. En el caso de Brasil, esto se puede interpretar a la luz del 
Cuadro 1 - Porcentaje ${ }^{I}$ de LRE en Argentina y Brasil en relación al total según los datos del PELA

\begin{tabular}{ll}
\hline Base & Porcentajes en relación con el total \\
\hline Argentina 2003-2007 & $12,38 \%(32 / 257$ casos $)$ \\
Argentina 2007-2011 & $10,91 \%(28 / 256$ casos $)$ \\
Argentina 2009-2013 & $18,57 \%(48 / 257$ casos $)$ \\
Brasil 2002-2006 & $14,18 \%(73 / 513$ casos $)$ \\
Brasil 2007-2011 & $19,38 \%(99 / 513$ casos $)$ \\
\hline
\end{tabular}

Fuente: El autor, a partir de Alcántara Sáez (2015).

${ }^{\text {I }}$ Los porcentajes y los números totales pueden no coincidir con exactitud, dado que se trata de casos válidos, expuestos a partir de las características de procesamiento del paquete SPSS. Asimismo, para facilitar la lectura, en los cuadros siguientes, se simplifican los porcentajes.

${ }^{\text {II }}$ Dada la legislación existente en Argentina, el mandato de los diputados es por cuatro años, renovándose la mitad de la Cámara cada dos años. Por ello, se superponen las fechas. La encuesta de referencia implica considerar a las cohortes por separado, de ahí que los datos no se superpongan.

consenso desarrollista sobre el que se erigieron las políticas del Partido dos Trabalhadores (PT). Mientras que en un primer momento el gobierno de Lula generó resistencias en el mundo de los negocios, luego se produjo un acercamiento que se mantuvo - al menos - durante la primera presidencia de Dilma Rousseff entre 2010 y 2014 (Diniz y Boschi 2007).

Al mismo tiempo, en Argentina, el incremento en el último período legislativo en Argentina puede imputarse a una política más vasta. Desde la crisis institucional que sufrió el país en 2001-2002 a la actualidad, tanto el presidente Duhalde como sus sucesores han buscado estrechar lazos con el mundo empresarial. De este modo, se generaron instancias de representación en diferentes espacios del poder ejecutivo nacional. ¿Podría sostenerse algo similar en el poder legislativo? Para responder tal pregunta, debemos ir a la distribución por partido los LRE.

Como podemos ver en el Cuadro 2, se parte de una situación de origen. El PJ, fiel a cierta tradición de paritarismo que implicaba la participación de obreros y empresarios - más los primeros que los últimos - encuadrados en el partido poseía la mayoría de los LRE en 2003. En este marco, el radicalismo mantiene también un peso significativo como fuerza que contiene a este grupo.

Sin embargo, en el período siguiente las cosas se reconfiguran con una hegemonía mayor del PJ, una importante pérdida de peso del radicalismo y la irrupción de Propuesta Republicana-PRO.

Finalmente, la oleada que va de 2009 a 2013 nos muestra otro escenario: al fragmentarse el PJ, también sus LRE se dispersan. Y gana peso el radicalismo. En este punto, es significativo destacar que el PRO, a pesar de lo que sostiene la literatura (Cf. Vommaro, Morresi \& Bellotti 2015), poseía por ese entonces, al igual que en el período posterior, escasos representantes correspondientes a esta categoría.

Resulta curioso, entonces, que para 2009-2013 la UCR recupera su capacidad de incorporar a este tipo de representante - lo cual puede ligarse a la presencia de dicho partido en las regiones agroindustriales y agrícola-ganaderas $^{8}$. Mientras que, al mismo tiempo, el partido gobernante FPV-PJ pierde su capacidad para involucrar a estos y a otros sectores empresariales. Por el contrario, los encontramos en otras corrientes peronistas (peronismo, Peronismo Federal). De este modo, si bien las fuerzas peronistas en su conjunto
${ }^{8}$ Es importante señalar que en marzo de 2008 se abrió un conflicto entre el gobierno kirchnerista y diversas entidades que nucleaban a distintos representantes del 
Cuadro 2 - Porcentaje de LRE en Argentina distribuidos por período legislativo y por partido político

\begin{tabular}{lccc}
\hline Partido Político/Período & $\mathbf{2 0 0 3 - 2 0 0 7}$ & $\mathbf{2 0 0 7 - 2 0 1 1}$ & $\mathbf{2 0 0 9 - 2 0 1 3}$ \\
\hline PJ & $41,8 \%(14)$ & - & - \\
Unión Cívica Radical-UCR & $25,0 \%(8)$ & $8,7 \%(3)$ & $36 \%(17)$ \\
Partidos Provinciales & - & $7,3 \%(2)$ & - \\
Otros partidos & $33,2 \%(10)$ & $32 \%(9)$ & $15 \%(7)$ \\
FPV-PJ & - & $44 \%(12)$ & $10 \%(5)$ \\
PRO & - & $8 \%(2)$ & $6 \%(3)$ \\
Peronismo Federal & - & - & $20 \%(10)$ \\
Peronismo & - & - & $13 \%(6)$ \\
Total & $100 \%(32)$ & $100 \%(28)$ & $100 \%(48)$ \\
\hline
\end{tabular}

Fuente: El autor, a partir de Alcántara Sáez (2015).

Nota: Vale la pena que se distingue al Partido Justicialista-PJ del Frente para la Victoria-FPV-PJ, del Peronismo Federal y del peronismo en función de las escisiones internas que ha sufrido el PJ.

empresariado agropecuario a partir del debate por el incremento de las retenciones a las exportaciones (principalmente cereales). Este enfrentamiento permaneció abierto durante los siguientes años de la mencionada gestión. poseen la mayoría de representantes corporativos, el peso decrece y la UCR avanza. Insisto, esto nos permite señalar algunas cuestiones significativas. No es el PRO - al menos en lo que atañe a este universo y en la Cámara Baja - el representante del poder económico. Sino que dicho rol lo intentan expresar las distintas facciones del peronismo y el radicalismo.

¿Cómo puede leerse este argumento en clave comparativa con Brasil? Antes de pasar a tratar esta cuestión, vale la pena tener en cuenta la mayor complejidad del parlamento brasileño. Por ende, diferenciar oficialismo de oposición de un modo tajante, es sumamente complejo: los alineamientos, clivaje y el propio sistema de acuerdos parlamentarios son totalmente diferentes. De allí que, en lo atinente a la representación corporativa, nos encontremos con un equilibrio mucho mayor. Ahora bien, en trabajos previos, emergió una primera observación sobre la Cámara Alta: los líderes empresariales brasileños tendían a participar en partidos vinculados al proyecto militar de transición democrática (Donatello 2014). Luego, existe un segundo argumento, que surge de otros estudios sobre la temática: la existencia de un intento del PT para incrementar sus vínculos con el mundo empresarial ¿Son ambas premisas certeras al tratar la Cámara Baja?

Considerando lo expuesto, Brasil muestra cifras que expresan la mencionada heterogeneidad. En el Cuadro 3, puede observarse que el PTB lideraba en cantidad de LRE en 2003-2007, seguido por el PMDB y el PFL, mientras que el PP y el PSDB también tenían cuotas significativas. El resto, aparecía en otras fuerzas incluido el PT. En ese sentido el intento del partido gobernante de conseguir apoyo empresarial en los inicios de su experiencia, no se tradujeron en un éxito significativo en este terreno. Estas tendencias se profundizan en 2007-2011, donde el PMDB, Democratas - nombre con el cual se reconvierte el PFL - y el PSDB ganan preeminencia en relación con el período anterior. Mientras que el PR adquiere también relevancia al respecto. Al mismo tiempo, la migración de LRE del PTB hacia otras fuerzas, puede obedecer a la pérdida de peso electoral este partido.

En relación con la vinculación de representantes empresariales con partidos herederos del proyecto militar de transición democrática, la hipótesis es relativamente plausible. Sí bien el equilibrio de los agentes que constituyen nuestro universo se encuentra balanceado en el vasto espectro parlamentario, las fuerzas 
Cuadro 3 - Porcentaje de LRE en Brasil distribuidos por período legislativo y por partido político

\begin{tabular}{lcc}
\hline Partido Político/Período & $\mathbf{2 0 0 2 - 2 0 0 6}$ & $\mathbf{2 0 0 6 - 2 0 1 1}$ \\
\hline Partido dos Trabalhadores-PT & $5,3 \%(4)$ & - \\
Partido do Movimento Democrático Brasileiro-PMDB & $15,8 \%(11)$ & $21,6 \%(21)$ \\
Partido da Frente Liberal-PFL/ Democratas & $15,8 \%(11)$ & $20,1 \%(20)$ \\
Partido Progressista-PP & $10,5 \%(8)$ & $8,9 \%(9)$ \\
Partido Trabalhista Brasileiro-PTB & $21,1 \%(15)$ & - \\
Partido da Social Democracia Brasileira-PSDB & $10,5 \%(8)$ & $13,3 \%(13)$ \\
Partido Liberal-PL & $5,3 \%(4)$ & - \\
Partido Popular Socialista-PPS & $5,3 \%(4)$ & - \\
Partido Socialista Brasileño-PSB & $5,3 \%(4)$ & - \\
Partido Democrático Trabalhista-PDT & $5,3 \%(4)$ & $4,3 \%(4)$ \\
Partido Social Cristão-PSC & - & $7,5 \%(7)$ \\
Partido da República-PR & - & $17,8 \%(17)$ \\
Partido Verde-PV & - & $3,5 \%(4)$ \\
Otros partidos & - & $3,0 \%(4)$ \\
Total & $100 \%(73)$ & $100 \%(99)$ \\
\hline
\end{tabular}

Fuente: El autor, a partir de Alcántara Sáez (2015).

mencionadas terminan teniendo la mayoría relativa en ambos períodos. En este punto, siempre que podamos considerar a PFL-Democratas, PP, PL y PR como fuerzas ligadas a los proyectos de ARENA y el Partido Democrata Social-PDS - ambos soportes civiles del gobierno autoritario de 1964-1985 - vemos que estas fuerzas pasan de tener un tercio a sumar casi la mitad de los LRE.

Sin embargo, es notable también la presencia de éstos en catch-all parties como el PMDB, que encabezó en su momento la oposición al régimen militar. Lo cual matiza bastante la imagen de una continuidad por derecha (Martins Rodrigues 2009).

A partir de esta caracterización, vale la pena interrogarse por los rasgos sociológicos de los agentes. En primer lugar, puede verse que el universo de referencia es marcadamente masculino. Ello puede ser autoevidente. Sin embargo, conviene refinar la mirada. Para ello, podemos comparar la dinámica de la representación femenina en ambos países en general. En Argentina las mujeres pasan de ser el 32,5\% de la cámara baja en 2003 (PELA 2004, p.32) a casi 37\% en la oleada de 2009 (PELA 2010a, p.54). En Brasil, van del 8\% en 2002 al 12\% en 2007 (PELA 2005, p.33; 2010b, p.39). ¿Sucede lo mismo con los LRE?

$\mathrm{Al}$ respecto, vemos que las cifras (Cuadro 4) no avanzan de manera análoga en el caso de los LRE. En ese sentido, podría sostenerse que - dentro de un universo donde el patriarcalismo empieza a desnaturalizarse - el mundo de la representación empresarial sigue resistiéndose a esa tendencia.

Si comparamos la presencia de mujeres LRE con lo que sucede en las cámaras empresariales o en los directorios de las empresas vemos que la realidad en este espacio es análoga (Kliksberg 2010, pp.3-4). Vale la pena destacar al respecto que - en paralelo a los espasmódicos intentos llevados a delante por los poderes legislativos de ambos países en relación con las leyes de cupos (Teixeira dos Santos \& Emerick Seabra 2009) - ha habido importantes iniciativas del poder ejecutivo. Tanto Argentina como Brasil fueron realizando 
Cuadro 4 - Porcentaje de LRE en Argentina y Brasil distribuidos por período legislativo y por sexo

\begin{tabular}{lccccc}
\hline $\begin{array}{l}\text { Período legis- } \\
\text { lativo/Sexo }\end{array}$ & $\begin{array}{c}\text { Argentina } \\
\mathbf{2 0 0 3 - 2 0 0 7}\end{array}$ & $\begin{array}{c}\text { Argentina } \\
\mathbf{2 0 0 7 - 2 0 1 1}\end{array}$ & $\begin{array}{c}\text { Argentina } \\
\mathbf{2 0 0 9 - 2 0 1 3}\end{array}$ & $\begin{array}{c}\text { Brasil } \\
\mathbf{2 0 0 2 - 2 0 0 6}\end{array}$ & $\begin{array}{c}\text { Brasil } \\
\mathbf{2 0 0 7 - 2 0 1 1}\end{array}$ \\
\hline Varón & $85,5 \%(27)$ & $83 \%(23)$ & $94 \%(45)$ & $100 \%(73)$ & $91 \%(90)$ \\
Mujer & $14,5 \%(5)$ & $17 \%(5)$ & $6 \%(3)$ & - & $9 \%(9)$ \\
Total & $100 \%(32)$ & $100 \%(28)$ & $100 \%(48)$ & $100 \%(73)$ & $100 \%(99)$ \\
\hline
\end{tabular}

Fuente: El autor, a partir de Alcántara Sáez (2015).

avances con la llegada de mujeres a la presidencia. Del mismo modo en que tanto Cristina Fernández, como Dilma Rousseff llevaron adelante políticas sobre este tema. Una modalidad fue el nombramiento de funcionarias ligadas a la gestión de lo económico. Por ejemplo, Debora Giorgi en la cartera de Producción o Noemí Rial (Viceministra) en la de Trabajo en Argentina. O bien, erigiéndolas a la cabeza de empresas públicas como fue el caso de Maria das Graças Foster en la poderosa empresa petrolera de bandera nacional Petrobras.

Otra consideración, sobre la que vale la pena detenerse está directamente asociada a la dominación patriarcal. Y es el supuesto carácter gerontocrático de la población de referência. En ese sentido, hay varios elementos sobre los cuales hacer consideraciones. Sin poseer cifras exactas sobre lo que sucede en las cámaras patronales, puede hipotetizarse por los rasgos de algunos representantes emblemáticos existe tal tendencia a que adultos mayores ocupen posiciones de privilegio. Esto es más difícil de determinar en los directorios de las grandes empresas multinacionales. Y, en algún modo va de suyo en las grandes empresas nacionales de carácter local (Cuadro 5). ¿Cómo ha evolucionado está cuestión en los LRE?

Es interesante observar en este punto las poblaciones de LRE de ambos países se comportan de un modo bastante diferente a la del resto de legisladores. En Argentina la cifra total de legisladores mayores a 65 años oscila entre el 6 y el 8, 6\%. En Brasil, pasan del 12 al 25\% en los períodos parlamentarios de referencia ${ }^{9}$. Sin embargo, en el terreno de los LRE, vemos que - en ambos países - la población es más joven. Aunque, significativamente, la población mayor de 65 años aumente relativamente: dan un salto del 0 al 10\% en Argentina para el período 2009-2013 y del 5\% al 15\% en Brasil en las cohortes de referencia (Cf. PELA 2004, p.33; 2005, p.33; 2008, p.39; 2010a, p.39; 2010b, p.39). Entonces, a modo hipotético, podemos aventurar que se trata de población más joven si se toma esta instancia empresarial en comparación con otras.

Cuadro 5 - Porcentaje de LRE en Argentina y Brasil distribuidos por período legislativo y por edades

\begin{tabular}{lccccc}
\hline $\begin{array}{l}\text { Período legislativo/ } \\
\text { Edades }\end{array}$ & $\begin{array}{c}\text { Argentina } \\
\text { 2003-2007 }\end{array}$ & $\begin{array}{c}\text { Argentina } \\
\mathbf{2 0 0 7 - 2 0 1 1}\end{array}$ & $\begin{array}{c}\text { Argentina } \\
\mathbf{2 0 0 9 - 2 0 1 3}\end{array}$ & $\begin{array}{c}\text { 2002-2006 } \\
\text { 20007il }\end{array}$ & $\begin{array}{c}\text { Brasil } \\
\text { 20011 }\end{array}$ \\
\hline Menor de 40 & $27 \%(9)$ & $8 \%(2)$ & $6 \%(3)$ & $6 \%(4)$ & $17 \%(17)$ \\
Entre 40 y 65 & $73 \%(23)$ & $92 \%(26)$ & $84 \%(40)$ & $89 \%(65)$ & $68 \%(67)$ \\
Mayor de 65 & - & - & $10 \%(5)$ & $5 \%(4)$ & $15 \%(15)$ \\
Total & $100 \%(32)$ & $100 \%(28)$ & $100 \%(48)$ & $100 \%(73)$ & $100 \%(99)$ \\
\hline
\end{tabular}

Fuente: El autor, a partir de Alcántara Sáez (2015). 
Ahora bien, de manera ligada a la cuestión etaria, pero ya no a la dominación patriarcal, tenemos el clásico tópico de las generaciones. En ese sentido, el momento histórico en el cual los legisladores manifiestan haber iniciado su trayectoria política es un buen indicador del tipo de sociedad en la cual se formaron.

Vemos que un importante número de LRE en ambos países se ha vinculado a la vida política con posterioridad a los años 80 del siglo pasado. Ello podría interpretarse como una cuestión biológica. Sin embargo, si comparamos este dato con la descripción anterior, y con las cifras correspondientes a los legisladores en general, podemos sostener que el rasgo obedece a otro factor.

Si vamos a la distribución del total de legisladores, en Argentina puede verse que en 2003 sólo un tercio de la Cámara Baja había iniciado algún tipo de militancia en los años 80 del siglo pasado (PELA 2004, p. 21). Mientras que para 2009 ya era la mitad (PELA 2010a, p. 22). En Brasil, en 2002, más del $40 \%$ de los diputados habían iniciado su militancia a partir de esa época (PELA 2005, p. 20). Y, en el período posterior superaban el 50\% (PELA 2010b, p. 22).

Aquí es donde los LRE también rompen con algunas prenociones al respecto. Ello se debe a que progresivamente el número de aquellos que comenzaron su socialización política en los últimos treinta años es superior al resto de legisladores. Es decir, dentro de un medio que fue proclive en el siglo XX a una alianza con el poder militar, vemos otra cosa. En ambos países se da el mismo fenómeno: los LRE son jóvenes y se vincularon a la política en democracia. Con lo cual, la reflexión debe desplazarse hacia otro terreno: el significado y la dinámica de este fenómeno.

El ciclo de regímenes democráticos que se abre en América Latina nos muestra un incremento tanto en la participación, como en la movilización de los ciudadanos y en la ampliación de la agenda de derechos. Democracia en los últimos treinta años, es un enunciado que adquiere un significado distinto al pasado. En este punto, el mundo empresarial, lejos quedarse acotado a antiguas estructuras organizativas y modalidades de participación parece manifestarse de otra manera. Sí vemos los datos del Cuadro 6, tenemos que las elecciones competitivas aparecen como una herramienta válida, que va ganando peso en el mundo empresarial. Sobre todo, en generaciones que se incorporan al universo de la representación empresarial más tempranamente.

Acá, tampoco podemos dejar de soslayar la voluntad de los propios partidos políticos de tener sus ramas vinculadas a estos sectores. Y, en este punto, las diferencias entre ambos países plantean elementos que abonan a esta hipótesis. Mientras que en Brasil el camino parece organizado en torno a fuerzas identificadas tanto con el espectro de centro derecha como con sus catch-all parties, en Argentina se da a través de partidos tradicionalmente populares. Es el caso de

Cuadro 6 - Porcentaje de LRE en Argentina y Brasil distribuidos por período legislativo y década de inicio de su trayectoria política

\begin{tabular}{lccccc}
\hline $\begin{array}{l}\text { Período Legislativo/ Década de } \\
\text { inicio de su trayectoria política }\end{array}$ & $\begin{array}{c}\text { Argentina } \\
\mathbf{2 0 0 3 - 2 0 0 7}\end{array}$ & $\begin{array}{c}\text { Argentina } \\
\mathbf{2 0 0 7 - 2 0 1 1}\end{array}$ & $\begin{array}{c}\text { Argentina } \\
\mathbf{2 0 0 9 - 2 0 1 3}\end{array}$ & $\begin{array}{c}\text { Brasil } \\
\mathbf{2 0 0 2 - 2 0 0 6}\end{array}$ & $\begin{array}{c}\text { Brasil } \\
\mathbf{2 0 0 7 - 2 0 1 1}\end{array}$ \\
\hline Antes de la década de 1980 & $42 \%(13)$ & $55 \%(16)$ & $50 \%(24)$ & $42 \%(30)$ & $30 \%(30)$ \\
A partir de la década de 1980 & $58 \%(19)$ & $45 \%(12)$ & $38 \%(18)$ & $47 \%(34)$ & $63 \%(63)$ \\
No recuerda/No contesta & - & - & $12 \%(6)$ & $11 \%(9)$ & $7 \%(6)$ \\
Total & $100 \%(32)$ & $100 \%(28)$ & $100 \%$ & $100 \%(73)$ & $100 \%(99)$ \\
\hline
\end{tabular}

Fuente: El autor, a partir de Alcántara Sáez (2015). 
la Unión Cívica Radical, partido con una historia centenaria que reunió demandas de ampliación de derechos cívicos. O el peronismo, históricamente ligado a reclamos ligados a demandas provenientes del mundo del trabajo y a una fuerte impronta nacionalista. Pero que, sin embargo, se caracterizó por un pragmatismo que le permitió acercarse a posiciones neoliberales. Ambas, fueron fuerzas plebeyas en sus orígenes. Y, al mismo tiempo, incorporaron a las distintas masas de inmigrantes a la vida pública. También debe mencionarse que, a partir de 1983 y hasta la Alianza Cambiemos, las fuerzas de centroderecha fueron relativamente minoritarias en términos electorales.

De todos modos, para determinar el apego de los LRE a formas más ligadas a la primera modernidad o las transformaciones societales más recientes, debemos recurrir a otros indicadores. Por ejemplo, su estado civil. Este factor nos dice mucho sobre los estilos de vida (Beck-Gernshein 2003).

En ambos países, puede verse (Cuadro 7) que el total de diputados poseen un comportamiento análogo. En la medida en que pasan los períodos, la cifra de quienes se declaran casados oscila en torno al $75 \%$, mientras que los divorciados avanzan del 10\% al 15\% (PELA 2004, p. 34; 2008, p.41; 2005, p.34; 2010b, p. 40). Una excepción se da en Argentina a partir de 2009, donde los casados pasan a ser el 55\% (PELA 2010a, p.40). Ello se da tanto por el incremento de los solteros (14\%) y los separados (23\%). ¿Sucede lo mismo con los LRE?

Los LRE comienzan en Argentina asimilados a la tendencia general. Luego, hacia 2009 superan en cantidad de separados a la misma. En Brasil, a partir de los datos disponibles, vemos que la transformación también es marcada. ¿El paulatino descenso de los casados y el incremento de las personas que manifiestan estar solteras o separadas es una característica que nos habla de mutaciones en la sociabilidad doméstica? En función de la literatura mencionada, sabemos que no podemos dar una respuesta unívoca. Sin embargo, el incremento de los divorcios expresa cambios evidentes en las pautas conyugales que siguen tendencias societales generales en lo relativo a las modalidades de familia.

Otro indicador al respecto es la auto identificación religiosa (Cuadro 8). Al respecto existe una discusión abierta sobre el carácter socio religioso de las élites dirigentes. En el caso de Brasil, el debate es sumamente actual (Neri 2011). Sin embargo, una diferencia que no podemos soslayar es el tipo de penetración del mundo católico en el Estado en ambos países durante el siglo XX. Mientras que en Argentina, buena parte de los políticos aceptaron y abonaron a la construcción del mito de un país católico (Mallimaci 2015); en Brasil la realidad fue muy diferente. En parte por la formación de las élites militares que controlaron el Estado durante el gobierno autoritario, inspirados en una ideología positivista. Y, al mismo tiempo, por la temprana incorporación de legisladores que hacían de su confesión una seña de identidad política: incluso, los evangélicos configuran un corte transversal en el Parlamento

Cuadro 7 - Porcentaje de LRE corporativos en Argentina y Brasil distribuidos por período legislativo y estado civil

\begin{tabular}{lccccc}
\hline $\begin{array}{l}\text { Período legislativo/ } \\
\text { Estado Civil }\end{array}$ & $\begin{array}{c}\text { Argentina } \\
\text { 2003-2007 }\end{array}$ & $\begin{array}{c}\text { 2007-2011 } \\
\text { 2009-2013 }\end{array}$ & $\begin{array}{c}\text { 2002-2006 } \\
\text { 2007-2011 }\end{array}$ \\
\hline Soltero/viudo & $8 \%(3)$ & $12 \%(3)$ & & $5 \%(4)$ & $9 \%(9)$ \\
Casado/Unión libre & $77 \%(24)$ & $70 \%(20)$ & $56 \%(27)$ & $90 \%(65)$ & $69 \%(68)$ \\
Divorciado o Separado & $15 \%(5)$ & $18 \%(5)$ & $44 \%(21)$ & $5 \%(4)$ & $22 \%(22)$ \\
Total & $100 \%(32)$ & $100 \%(28)$ & $100 \%(48)$ & $100 \%(73)$ & $100 \%(99)$ \\
\hline
\end{tabular}

Fuente: El autor, a partir de Alcántara Sáez (2015). 
Cuadro 8 - Porcentaje de LRE en Argentina y Brasil distribuidos por período y auto identificación religiosa

\begin{tabular}{|c|c|c|c|c|c|}
\hline $\begin{array}{l}\text { Período/Auto iden- } \\
\text { tificación religiosa }\end{array}$ & $\begin{array}{l}\text { Argentina } \\
\text { 2003-2007 }\end{array}$ & $\begin{array}{l}\text { Argentina } \\
2007-2011\end{array}$ & $\begin{array}{l}\text { Argentina } \\
2009-2013\end{array}$ & $\begin{array}{c}\text { Brasil } \\
2002-2006\end{array}$ & $\begin{array}{c}\text { Brasil } \\
2007-2011\end{array}$ \\
\hline Católico & $77 \%(24)$ & $91 \%(25)$ & $80 \%(38)$ & $74 \%(54)$ & $66 \%(65)$ \\
\hline Otras creencias ${ }^{\mathrm{I}}$ & $23 \%(8)$ & $9 \%(3)$ & $20 \%(10)$ & $26 \%(19)$ & $34 \%(34)$ \\
\hline Total & $100 \%(32)$ & $100 \%(28)$ & $100 \%(48)$ & $100 \%(73)$ & $100 \%$ (99) \\
\hline
\end{tabular}

Fuente: El autor, a partir de Alcántara Sáez (2015).

I Aquí incluimos, fundamentalmente, a protestantes históricos y evangélicos. A los fines de simplificar la lectura, unimos a éstos otras categorías cuya baja incidencia estadística nos permite posicionarlas entre alternativas o en disidencia a la socialización católica: tal es el caso de los ateos o de aquellos que prefirieron no responder la pregunta.

brasileño (Cf. Freston 1993). ¿Cómo se han autoidentificado quienes integran nuestro objeto en estos años?

Si tomamos dicha dimensión para los diputados de ambos países en general, tenemos en Argentina una amplia mayoría católica, con muy poco espacio para el agnosticismo o para el ateísmo (PELA 2004, p.31; 2008, p.38; 2010a, p.38). En Brasil, directamente, estos últimos no aparecen prácticamente registrados (PELA 2005, p.31; 2010b, p.39). Sin embargo, el porcentaje de católicos se mantiene en ambos períodos en torno a tres cuartas partes de la cámara baja. Mientras que el resto se identifica con el protestantismo histórico o el evangelismo.

Yendo a los LRE, vemos que estos rasgos se mantienen. En Argentina el número de católicos es mayor a la del resto de legisladores. En relación la minoría que se identifican con otras religiones - al no existir datos de cuáles son - puede suponerse, por la vía cualitativa, que se trata de personas ligadas al mundo judío o protestante histórico. En Brasil, en cambio, vemos que las confesiones protestantes históricas o evangélicas ganan terreno: de una cuarta parte a un tercio de los LRE se identifican con este mundo.

Ello nos habla de un mayor pluralismo religioso en el caso de Brasil, contra una marcada tendencia católica en el de Argentina. En ese sentido, la elección de un sumo pontífice romano de origen argentino no parece haber tenido efecto. Dado que ya antes de este acontecimiento, tanto los legisladores en general, como aquellos ligados al mundo empresarial se manifestaban mayoritariamente católicos. ¿Es esto un indicador de un espacio más tradicional en Argentina en comparación con otro más abierto en Brasil?

Aquí tampoco la respuesta puede ser unívoca. Fundamentalmente, porque la autoidentificación puede tener varios significados. Uno puede ser, efectivamente la afirmación identitaria. Otro, la aceptación de una representación que se propone como hegemónica. Asimismo, el pluralismo religioso no necesariamente es un signo de ampliación de la agencia. Por el contrario, también puede significar que minorías activas hagan de la tradición (evangélica, neoevangélica o protestante histórica) su razón de ser. En todo caso, podríamos hipotetizar que quienes forman nuestro universo - aun siguiendo pautas generales - guardan una extrema cautela a la hora de responder sobre esta temática.

Otro rasgo sociológico que emerge del estudio de las características de los legisladores está ligado a su sociabilidad educativa. En ese sentido, el máximo nivel de estudios alcanzados nos puede ilustrar al respecto y nos brinda datos para interpretar un tema ya clásico en las ciencias sociales: sus capitales culturales (Bourdieu 1987). Si seguimos el recorrido trazado hasta ahora, 
vemos que la devaluación de las credenciales y la proliferación de los estudios de posgrado, son fenómenos que caracterizan a ambos cuerpos por igual. En Argentina, en 2003 tenemos que casi una quinta parte de los diputados poseía estudios de posgrado, mientras que más del $60 \%$ había realizado al menos estudios superiores. Estas cifras se van incrementando paulatinamente, con un salto en 2007, donde más del 40\% había alcanzado el nivel más elevado, para bajar en 2009 (PELA 2004, p. 35; 2008, p. 41; 2010a, p. 41). Pero siempre con tasas de alta escolarización superior. En Brasil, en los dos períodos sobre los que disponemos información, la cantidad de diputados con estudios de posgrado es mayor (un tercio, aproximadamente, en ambos) mientras que el grado universitario es alcanzado siempre por más de la mitad (PELA 2005, p. 35; 2010b, p. 41).

En el universo de los LRE, vemos que esta realidad es bastante diferente (Cuadro 9). En Argentina, recién en los últimos dos períodos nos encontramos con personas con formación de posgrado, con niveles inferiores al resto de legisladores en 2007, logrando superarlos en 2009. Sin embargo - con la excepción del último período - es mayor el número de personas que alcanzaron el grado universitario. Es decir, vemos un tipo de vínculo con la educación superior que parece estar ligado a una carrera empresarial, en sectores con una demanda de especialización más acotada en lo académico. Ello nos permitiría inferir una fuerte presencia de personas vinculadas a emprendimientos familiares propios, que no se encuentran expuestos a la competencia del mundo de la alta gerencia. En Brasil, nos encontramos con un panorama similar. Y, con un fuerte peso de diputados que sólo alcanzaron el nivel medio.

Estos datos pueden ser interpretados de manera solidaria con aquello que hipotetizamos en relación con la cuestión generacional: la representación sectorial aparece más vinculada al territorio que a la rama de la producción. De acuerdo con el argumento anterior, si vamos a la totalidad de diputados, vemos realidades diferentes en cada país. En Argentina, en 2003 el 12\% de los legisladores habían estudiado en el exterior (PELA 2004, p. 35). Para aumentar hasta el 24\% en 2009 (PELA 2010a, p.41). La delantera de los destinos escogidos es España, seguido de EE.UU y el Reino Unido. En cambio, en Brasil, vemos porcentajes menores: $17 \%$ y $13 \%$ para los dos períodos sobre los que poseemos información (PELA 2005, p. 35; PELA 2010b, p. 41). Siendo los las universidades norteamericanas y británicas las más privilegiadas. Esta diferencia, puede imputarse al desarrollo desigual del sistema de posgrados en ambos países (Barsky \& Dávila 2012) ¿Cómo se manifiestan estas tendencias en el terreno de los LRE (Cuadro 10)?

En el caso de los LRE argentinos, vemos una realidad distinta a lo que sucede con el resto de parlamentarios. Recién podemos ver que en 2007 aparecen los primeros casos, en una suma inferior a la proporción total. Y, lo curioso es que superan dicha cifra en 2009. Es decir, podría sostenerse que,

Cuadro 9 - Porcentaje de LRE en Argentina y Brasil distribuidos por período legislativo y máximo nivel educativo alcanzado

\begin{tabular}{lccccc}
\hline $\begin{array}{l}\text { Período legislativo/ Máximo nivel } \\
\text { educativo alcanzado }\end{array}$ & $\begin{array}{c}\text { Argentina } \\
\mathbf{2 0 0 3 - 2 0 0 7}\end{array}$ & $\begin{array}{c}\text { Argentina } \\
\mathbf{2 0 0 7 - 2 0 1 1}\end{array}$ & $\begin{array}{c}\text { Argentina } \\
\mathbf{2 0 0 9 - 2 0 1 3}\end{array}$ & $\begin{array}{c}\text { Brasil } \\
\mathbf{2 0 0 2 - 2 0 0 6}\end{array}$ & $\begin{array}{c}\text { Brasil } \\
\mathbf{2 0 0 7 - 2 0 1 1}\end{array}$ \\
\hline Posgrado & - & $17 \%(5)$ & $34 \%(16)$ & $16 \%(12)$ & $12 \%(12)$ \\
Universitario & $77 \%(25)$ & $70 \%(20)$ & $20 \%(10)$ & $74 \%(54)$ & $56 \%(55)$ \\
Educación básica (primario y secundario) & $23 \%(7)$ & $13 \%(3)$ & $46 \%(22)$ & $10 \%(7)$ & $32 \%(32)$ \\
Total & $100 \%(32)$ & $100 \%(28)$ & $100 \%(48)$ & $100 \%(73)$ & $100 \%(99)$ \\
\hline
\end{tabular}

Fuente: El autor, a partir de Alcántara Sáez (2015). 
Cuadro 10 - Porcentaje de LRE en Argentina y Brasil que realizaron estudios en el extranjero distribuidos por período legislativo y por país donde estudiaron

\begin{tabular}{lccccc}
\hline & $\begin{array}{c}\text { Argentina } \\
\text { 2003-2007 }\end{array}$ & $\begin{array}{c}\text { Argentina } \\
\mathbf{2 0 0 7 - 2 0 1 1}\end{array}$ & $\begin{array}{c}\text { Argentina } \\
\mathbf{2 0 0 9 - 2 0 1 3}\end{array}$ & $\begin{array}{c}\text { Brasil } \\
\mathbf{2 0 0 2 - 2 0 0 6}\end{array}$ & $\begin{array}{c}\text { Brasil } \\
\mathbf{2 0 0 7 - 2 0 1 1}\end{array}$ \\
\hline $\begin{array}{l}\text { \% Con estudios } \\
\text { en el exterior }\end{array}$ & $0 \%$ & $\begin{array}{c}17 \% / 100 \% \\
(5 / 28)\end{array}$ & $\begin{array}{c}37 \% / 100 \% \\
(18 / 48)\end{array}$ & $\begin{array}{c}6 \% / 100 \% \\
(4 / 73)\end{array}$ & $\begin{array}{c}8 \% / 100 \% \\
(8 / 99)\end{array}$ \\
\hline
\end{tabular}

Fuente: El autor, a partir de Alcántara Sáez (2015).

luego de ir a la zaga de sus pares, quienes se encuentran en la intersección entre mundo político y empresarial empiezan a trasnacionalizarse por la vía educativa de manera tardía. Incluso, por la distribución por países, puede verse que no hay una tendencia definida, como lo puede ser España para buena parte de sus colegas. Lo cual, puede interpretarse como un rasgo que refuerza el argumento sobre el carácter parroquial de su socialización. En Brasil, vemos que para los dos períodos, esta característica de arraigo al territorio se mantiene en ambos. En un parlamento menos trasnacionalizado (al menos en el terreno de los estudios superiores), vemos que la capa ligada a los intereses empresariales conserva sus características centrípetas.

De acuerdo con esta descripción, ¿Podemos sostener que las diferencias se ligan a estructuras sociales contrapuestas? Para ello, es central ver las características de los predecesores. Y establecer en qué medida hay un cierre social previo (Parkin 1978), o pautas de reproducción de tal o cual rasgo categorial. Un primer rasgo es el estatus profesional de los padres (Cuadro 11).

En ambos países, en función de la información disponible, podemos ver una gran heterogeneidad. No hay una marcada presencia de una categoría socioocupacional de los padres de los LRE (Cuadro 12) en ninguno de los dos países. En Argentina, los padres comerciantes parecen mantener cierta regularidad. También los agricultores y jornaleros, junto con los profesionales independientes o los propios empresarios y gerentes van ocupando las mayores frecuencias. Del mismo modo en que hay una tenaz minoría de hijos de obreros o empleados. En Brasil, nos encontramos con un universo - a partir de los alcances de la fuente - igual de heterogéneo.

Cuadro 11 - Distribución porcentual de las profesiones de los padres de los LRE por período legislativo y por país

\begin{tabular}{|c|c|c|c|c|c|}
\hline $\begin{array}{l}\text { Período Legislativo y país/Profesión } \\
\text { del padre }\end{array}$ & $\begin{array}{l}\text { Argentina } \\
\text { 2003-2007 }\end{array}$ & $\begin{array}{l}\text { Argentina } \\
2007-2011\end{array}$ & $\begin{array}{l}\text { Argentina } \\
2009-2013\end{array}$ & $\begin{array}{c}\text { Brasil } \\
\text { 2002-2006 }\end{array}$ & $\begin{array}{c}\text { Brasil } \\
2007-2011\end{array}$ \\
\hline $\begin{array}{l}\text { Empleado público/ Fuerzas de } \\
\text { seguridad/ }\end{array}$ & $21 \%(7)$ & - & $6 \%(3)$ & $21 \%(15)$ & $4 \%(4)$ \\
\hline Alto funcionario público/ Magistrado & - & - & - & $16 \%(12)$ & $9 \%(9)$ \\
\hline Agricultor/jornalero & - & $22 \%(6)$ & $21 \%(10)$ & $21 \%(15)$ & $15 \%(15)$ \\
\hline Productor agropecuario & - & & & & $9 \%(9)$ \\
\hline Comerciante & $29 \%(9)$ & $26 \%(7)$ & $19 \%(9)$ & $16 \%(12)$ & $11 \%(10)$ \\
\hline Empresario Industrial/ Gerente & $23 \%(7)$ & - & $16 \%(8)$ & $16 \%(12)$ & $20 \%(20)$ \\
\hline $\begin{array}{l}\text { Empleado (sin especificar)/ } \\
\text { Obrero/Bancario }\end{array}$ & $13 \%(4)$ & $9 \%(3)$ & $10 \%(5)$ & $5 \%(4)$ & $8 \%(8)$ \\
\hline $\begin{array}{l}\text { Profesional independiente/ Profesor } \\
\text { Universitario/ Docente/Periodista }\end{array}$ & $14 \%(5)$ & $43 \%(12)$ & $28 \%(13)$ & $5 \%(3)$ & $24 \%(24)$ \\
\hline Total & $100 \%(32)$ & $100 \%(28)$ & $100 \%(48)$ & $100 \%(73)$ & $100 \%(99)$ \\
\hline
\end{tabular}

Fuente: El autor, a partir de Alcántara Sáez (2015). 
Cuadro 12 - Distribución porcentual de los máximos niveles educativos alcanzado por los padres de los LRE por período legislativo y por país

\begin{tabular}{|c|c|c|c|c|c|c|c|c|c|c|}
\hline \multirow{2}{*}{$\begin{array}{l}\text { Período Legislativo y país/ } \\
\text { Máximo nivel educativo } \\
\text { alcanzado por los padres }\end{array}$} & \multicolumn{2}{|c|}{$\begin{array}{l}\text { Argentina } \\
2003-2007\end{array}$} & \multicolumn{2}{|c|}{$\begin{array}{l}\text { Argentina } \\
2007-2011\end{array}$} & \multicolumn{2}{|c|}{$\begin{array}{l}\text { Argentina } \\
2009-2015\end{array}$} & \multicolumn{2}{|c|}{$\begin{array}{c}\text { Brasil } \\
\text { 2002-2006 }\end{array}$} & \multicolumn{2}{|c|}{$\begin{array}{c}\text { Brasil } \\
\text { 2007-2011 }\end{array}$} \\
\hline & $\mathbf{P}$ & $\mathbf{M}$ & $\mathbf{P}$ & $\mathbf{M}$ & $\mathbf{P}$ & M & $\mathbf{P}$ & M & $\mathbf{P}$ & $\mathbf{M}$ \\
\hline Universitarios o asimilados & $\begin{array}{l}40 \% \\
(12)\end{array}$ & $\begin{array}{l}8 \% \\
(2)\end{array}$ & $\begin{array}{l}43 \% \\
(12)\end{array}$ & $\begin{array}{l}34 \% \\
(10)\end{array}$ & $\begin{array}{l}28 \% \\
(13)\end{array}$ & $\begin{array}{l}12 \% \\
(5)\end{array}$ & $\begin{array}{l}16 \% \\
(12)\end{array}$ & $\begin{array}{l}5 \% \\
(3)\end{array}$ & $\begin{array}{l}37 \% \\
(37)\end{array}$ & $\begin{array}{l}28 \% \\
(28)\end{array}$ \\
\hline Secundarios & $\begin{array}{l}15 \% \\
(5)\end{array}$ & $\begin{array}{l}46 \% \\
(16)\end{array}$ & $\begin{array}{l}32 \% \\
(9)\end{array}$ & $\begin{array}{l}32 \% \\
(9)\end{array}$ & $\begin{array}{l}34 \% \\
(16)\end{array}$ & $\begin{array}{l}42 \% \\
(20)\end{array}$ & $\begin{array}{l}42 \% \\
(30)\end{array}$ & $\begin{array}{l}60 \% \\
(43)\end{array}$ & $\begin{array}{l}8 \% \\
(8)\end{array}$ & $\begin{array}{l}20 \% \\
(19)\end{array}$ \\
\hline Primarios & $\begin{array}{l}30 \% \\
(10)\end{array}$ & $\begin{array}{l}38 \% \\
(12)\end{array}$ & $\begin{array}{l}25 \% \\
(7)\end{array}$ & $\begin{array}{l}34 \% \\
(9)\end{array}$ & $\begin{array}{l}26 \% \\
(12)\end{array}$ & $\begin{array}{l}40 \% \\
(18)\end{array}$ & $\begin{array}{l}37 \% \\
(27)\end{array}$ & $\begin{array}{l}32 \% \\
(25)\end{array}$ & $\begin{array}{l}44 \% \\
(43)\end{array}$ & $\begin{array}{l}40 \% \\
(40)\end{array}$ \\
\hline Ninguno/ NS/NC & $\begin{array}{l}15 \% \\
(5)\end{array}$ & $\begin{array}{l}8 \% \\
(2)\end{array}$ & - & - & $\begin{array}{c}12 \% \\
(7)\end{array}$ & $\begin{array}{l}12 \% \\
(5)\end{array}$ & $\begin{array}{l}5 \% \\
(4)\end{array}$ & $\begin{array}{l}3 \% \\
(2)\end{array}$ & $\begin{array}{l}11 \% \\
(11)\end{array}$ & $\begin{array}{l}12 \% \\
(12)\end{array}$ \\
\hline Total & $\begin{array}{l}100 \% \\
(32)\end{array}$ & $\begin{array}{c}100 \% \\
(32)\end{array}$ & $\begin{array}{c}100 \% \\
(28)\end{array}$ & $\begin{array}{c}100 \% \\
(28)\end{array}$ & $\begin{array}{c}100 \% \\
(48)\end{array}$ & $\begin{array}{c}100 \% \\
(48)\end{array}$ & $\begin{array}{c}100 \% \\
(73)\end{array}$ & $\begin{array}{c}100 \% \\
(73)\end{array}$ & $\begin{array}{c}100 \% \\
(99)\end{array}$ & $\begin{array}{c}100 \% \\
(99)\end{array}$ \\
\hline
\end{tabular}

Fuente: El autor, a partir de Alcántara Sáez (2015).

Esto permite matizar la hipótesis reproductivista básica. Así como encontramos un grupo de hijos de empresarios, en ambos países tenemos personas que está encumbrándose a través de la política. La categoría socio-ocupacional de los padres, nos dice mucho más de los hijos. Sobre todo en lo atinente al capital social familiar acumulado. Lo cual vuelve a poner en el eje del análisis, el argumento sobre el rol de la actividad política como una puerta de oportunidades para personas que se encuentran en el mundo empresarial. Sin embargo, para establecer la pertinencia de esto, debemos ver qué pasa con los capitales educativos.

Como podemos ver en el cuadro anterior, tanto en Argentina como en Brasil, en la medida en que avanzan las cohortes, también avanza la cantidad de padres que han accedido a la educación superior. Es de notar, que esta evolución parece acompañar la dinámica de la formación de los hijos, expresada en el Cuadro 8. Así como los que alcanzaron la universidad en Argentina en 2009 retroceden en relación con la cohorte anterior, vemos que, en el caso de los predecesores, sucede algo parecido. Al mismo tiempo, es destacar cómo va diluyéndose en Argentina la categoría de aquellos que no tienen ningún tipo de estudios. Por el contrario, en Brasil, en los dos períodos, se mantiene.

De este modo, vemos que en lo que respecta a los capitales educativos no existe reproducción. Por el contrario, tenemos un esquema de movilidad social ascendente que se expresa en el terreno de la adquisición de competencias educativas. Ello refuerza el argumento anterior: la actividad política como un espacio más de acceso a oportunidades en paralelo a la vida económica. En ese sentido, es significativo ver las experiencias acumuladas en ese terreno por los familiares de las personas (Cuadro 13) que constituyen nuestro universo.

Es importante destacar que ante la pregunta ¿Algún familiar suyo se ha dedicado a la política, aunque actualmente no lo haga?, en ambos países es difícil establecer regularidades, más allá de que en Brasil, haya mayores porcentajes de LRE con parientes que sí lo estuvieron. Para comprender mejor la cuestión es importante ver las respuestas se les pregunta a los LRE sobre el máximo cargo (Cuadro 14) que ocupó el familiar nombrado (en este caso, aquel que lo fue en primer lugar).

Es significativo ver que la respuesta 'No ocupa/o ningún cargo', sea tan elevada. Con la excepción de los LRE brasileños de 2002, se encuentra en 
Cuadro 13 - Distribución porcentual por familiares que se vincularon o no a la política de los LRE por período legislativo y por país

\begin{tabular}{|c|c|c|c|c|c|}
\hline $\begin{array}{l}\text { Período legislativo y } \\
\text { país/ Presencia de } \\
\text { familiares dedicados } \\
\text { a la política }\end{array}$ & $\begin{array}{l}\text { Argentina } \\
\text { 2003-2007 }\end{array}$ & $\begin{array}{l}\text { Argentina } \\
2007-2011\end{array}$ & $\begin{array}{l}\text { Argentina } \\
2009-2013\end{array}$ & $\begin{array}{c}\text { Brasil } \\
2002-2006\end{array}$ & $\begin{array}{c}\text { Brasil } \\
2007-2011\end{array}$ \\
\hline $\mathrm{Si}$ & $29 \%$ (9) & $27 \%(8)$ & $40 \%$ (19) & $53 \%(39)$ & $65 \%(65)$ \\
\hline No & $71 \%(23)$ & $73 \%(20)$ & $60 \%(29)$ & $47 \%(34)$ & $35 \%(34)$ \\
\hline Total & $100 \%(32)$ & $100 \%(28)$ & $100 \%(48)$ & $100 \%(73)$ & $100 \%$ \\
\hline
\end{tabular}

Fuente: El autor, a partir de Alcántara Sáez (2015).

proporciones altas en el resto de los casos. En ese sentido, esta respuesta puede significar que - en paralelo a otras actividades - el pariente que pudo haber influido en la decisión de vincularse a la política partidaria fuera dirigente de un partido. Pero sin haber ocupado cargos legislativos o ejecutivos. Luego, con las excepciones de los entrevistados en Argentina en el período 2003-2007 y los de Brasil en 2007-2011, la amplia mayoría ocupó funciones ligadas a la vida política local.

En suma, estos datos desestiman la idea de la existencia de linajes políticos o de reproducción de un capital político acumulado por vía familiar (al menos para la población de referencia). Por el contrario, refuerzan la hipótesis emergente de que estamos ante grupos sociales que han aprovechado las oportunidades gestadas durante la democracia para extender sus actividades desde el mundo empresarial hacia la política. Y que, a lo sumo, han movilizado redes domésticas para hacerlo.

\section{Conclusiones: de la comprensión sociológica a la explicación política}

A partir de la caracterización realizada, vale la pena retomar los problemas que propuse al principio. En primer lugar, había hecho referencia al impacto de la globalización en la vida política, especialmente en el plano de la representación de intereses propios del mundo de los negocios. Tomando el doble prisma de las condiciones nacionales y el poder legislativo, vemos que las realidades de ambos países ilustran en alguna medida sobre el modo de funcionamiento complejo de estas realidades. En ese sentido, las características sociológicas de los LRE argentinos y brasileños nos hablan de un grupo social más bien ligado a las fuerzas centrípetas de las provincias o Estados que representan. Es decir, es difícil relacionar a estos agentes con condiciones de vida cosmopolita. Por el contrario, la vida social que parecen expresar se liga

Cuadro 14 - Distribución porcentual de los máximos cargos ocupados por los familiares dedicados a la política de los LRE nombrados en primer lugar por período legislativo, por país y por poder del Estado

\begin{tabular}{lccccc}
\hline $\begin{array}{l}\text { Período legislativo y país/ Máximo cargo ocupado } \\
\text { por el familiar nombrado en primer lugar }\end{array}$ & $\begin{array}{c}\text { Argentina } \\
\mathbf{2 0 0 3 - 2 0 0 7}\end{array}$ & $\begin{array}{c}\text { Argentina } \\
\mathbf{2 0 0 7 - 2 0 1 1}\end{array}$ & $\begin{array}{c}\text { Argentina } \\
\mathbf{2 0 0 9 - 2 0 1 3}\end{array}$ & $\begin{array}{c}\text { Brasil } \\
\mathbf{2 0 0 2}-\mathbf{2 0 0 6}\end{array}$ & $\begin{array}{c}\text { Brasil } \\
\mathbf{2 0 0 7 - 2 0 1 1}\end{array}$ \\
\hline Poder ejecutivo (nacional o provincial/estadual) & $22 \%(7)$ & $18 \%(5)$ & $16 \%(8)$ & $40 \%(29)$ & $32 \%(31)$ \\
Poder legislativo (nacional o provincial/estadual) & $56 \%(18)$ & $9 \%(2)$ & $52 \%(25)$ & $60 \%(44)$ & $29 \%(29)$ \\
No ocupa/ó & $22 \%(7)$ & $73 \%(21)$ & $32 \%(15)$ & $0 \%$ & $39 \%(39)$ \\
Total & $100 \%(32)$ & $100 \%(28)$ & $100 \%(48)$ & $100 \%(73)$ & $100 \%(99)$ \\
\hline
\end{tabular}

Fuente: El autor, a partir de Alcántara Sáez (2015). 
estrechamente a círculos sociales más bien restringidos. Este rasgo, queda más expuesto si se compara con las realidades de los legisladores en general. Éstos, parecen estar mucho más afectados por tendencias globales que aquellos.

En segundo lugar, otra problemática relacionada a nuestro objeto es aquella que se liga a los mecanismos de profesionalización política. Como se sostuvo al principio, no debe pensarse este fenómeno de manera unívoca. En ese sentido, lo que sucede en la intersección entre el mundo económico y la política es algo sumamente ilustrativo. Está claro que la ampliación de la democracia y el consecuente incremento de instancias de representación suponen que también se abran nuevas puertas para volcarse a la política como profesión. Con lo cual, que haya personas que sean a la vez profesionales de la política y aparezcan como cara visible de un emprendimiento económico o cómo representantes patronales de una rama de la producción expresa algo. Es lo que podemos caracterizar como una capa de especialistas en la representación patronal. Esto es algo que está facilitado normativamente en experiencias como la del lobbying norteamericano (Scott 2014). O que posee una tradición, como sucede en Francia a partir de la emergencia de lo que se ha denominado como permanents patronaux (Fraboulet 2010).

Sin embargo, constituye una novedad en estas latitudes. En el caso de Brasil, porque ya existen otros mecanismos de representación patronal: fundamentalmente, desde la década de 1930 y a lo largo de todo el siglo XX se desarrolló una matriz corporativa que persistió con las experiencias democráticas que se sucedieron a partir de la década de 1980 (Diniz \& Boschi 2000). Lo que resulta significativo es que, a las formas preexistentes, se suma la vía parlamentaria. $\mathrm{Si}$ bien no disponemos aún de datos para hacer una mirada retrospectiva, podría hipotetizarse que este fenómeno se da como respuesta al éxito electoral del PT. Sin embargo, se puede matizar esta afirmación, sí se tiene en cuenta que, antes que el PT crezca electoralmente, estas tendencias ya existían (Costa 2012). En Argentina, por su parte, vemos que ante la aparente ausencia de mecanismos institucionalizados emergen en este terreno espacios no siempre tematizados por las ciencias sociales vernáculas.

En ambos casos, las democracias han implicado el surgimiento de nuevas oportunidades para especializarse en la política desde un ángulo no necesariamente partidario. $\mathrm{O}$ bien, donde los partidos asumen instancias de representación multisectorial, de manera independiente de la lógica centrada en identidades relativamente férreas.

En relación con el tercer tópico, es interesante señalar lo que se vio sobre la relación entre vida doméstica y política. La ausencia de linajes políticos prácticamente en ambos casos nos habla de algo que puede interpretarse del siguiente modo: el ingreso al Parlamento como una manera de adquirir prestigio. Nuevamente, aquí aparece la arena democrática como un espacio de democratización hacia arriba. En este punto, la fuente nos habilita a ver la entrada. Tanto en la actividad política en general, como en el parlamento. Para poder tener una mejor percepción del fenómeno, se requiere ver qué sucede en la salida o cómo continúan los legisladores sus trayectorias. Sin embargo, con la información disponible, se puede hacer hincapié en la posibilidad que nos brindan los datos a la hora de ver un escenario sumamente heterogéneo.

Esta última característica nos conduce a reformular buena parte de los hallazgos previos (Donatello 2014; 2013). Visto el problema desde lo que ocurre en la Cámara Baja en ambos países, nos encontramos con que los contrastes son mucho menos marcados: por el contrario, podemos hipotetizar que nos encontramos con un grupo de especialistas en la representación de intereses que empieza a consolidarse. En ese sentido, podemos coincidir con la hipótesis formulada por Costa, Costa y Nunes (2014) sobre la profesionaliza- 
ción de senadores representantes empresariales en Brasil; éstos últimos, poseen carreras más largas que sus homólogos en la Cámara Baja

¿Esto es bueno o malo para la democracia de ambos países? Existieron numerosos debates a los inicios de las transiciones democráticas en América Latina sobre esta cuestión (Schmitter, Lembruch \& Streeck 1992). Luego, se fueron diluyendo a partir de las controvertidas experiencias de la década de 1990 (Heredia 2005). Reaparecen en los últimos años a la luz del debate sobre lo que se puede englobar bajo el término neodesarrollismo (Gaitan \& Boschi 2009).

No sabemos sí esta tendencia se reconfigurará en los próximos años. Sin embargo, los acontecimientos actuales ponen en cuestión el rumbo que se estaba siguiendo. En Brasil, a partir del impeachment a Dilma Rousseff y la posterior asunción de Temer a la presidencia. En Argentina, luego del cambio de gobierno que viene a poner fin a doce años de hegemonía peronista. En ambos países los escenarios nos abren nuevos interrogantes. Por lo que hemos visto, el juego es algo más claro en Brasil. En el sentido en que el vínculo entre el mundo de los negocios y las fuerzas que compiten con el PT, parece ser más definido. Esto no se observa tanto en el nivel de la representación parlamentaria, donde no encontramos diferencias entre ambos países. Por el contrario, puede comprenderse si se considera a la misma en una tradición donde se combinan diferentes maneras de representación que van desde la cámara, hasta los institutos liberais (Gros 2004) y el parlamento.

En Argentina, el esquema de representación es más débil, tanto en lo atinente a las cámaras, como a las fundaciones. Por ende, yendo al terreno parlamentario, lo que suceda con la Alianza Cambiemos y - más específicamente con el PRO - constituye un desafío analítico aún abierto. Por lo que hemos visto, allí no necesariamente se encuentran los representantes del mundo económico. En todo caso, esa puede ser una pretensión y un objetivo de dicha fuerza política.

Luis Miguel Donatello (ldonatello@ceil-conicet.gob.ar) es Doctor en Ciencias Sociales (Summa Cum Laude) por la Universidad de Buenos Aires y Doctor en Sociología por la Ecole des Hautes Etudes en Sciences Sociales de París. En la Actualidad es Investigador Adjunto del CONICET, Profesor Asociado Regular de la Facultad de Humanidades y Ciencias de la Universidad Nacional del Litoral - de la cual es Director del Departamento de Sociología. Vinculación Institucional: Centro de Estudios e Investigaciones Laborales-CEIL, CONICET, Buenos Aires, Argentina.

\section{Referencias}

Alcántara Sáez, M., 2012. El oficio de político. Madrid: Tecnos. ,2013. De políticos y política: profesionalización y calidad en el ejercicio público. Perfiles Latinoamericanos, 41, pp.19-44. DOI: 10.18504/p12141-019-2013 , ed., 2015. Base de datos. Proyecto Elites Latinoamericanas (PELA). Universidad de Salamanca.

Barsky, O. \& Dávila, M., 2012. El sistema de posgrados en la Argentina: tendencia y problemas actuales. Revista Argentina de Educación Superior, 4(5), pp.12-37.

Bauman, Z., 1999. En busca de la política. México: Fondo de Cultura Económica.

Beck-Gernshein, E., 2003. La reinvención de la familia: en búsqueda de nuevas formas de convivencia. Madrid: Paidos.

Bourdieu, P., 1987. Los Tres Estados del Capital Cultural. Sociológica, 2(5), pp.11-17. 2011. Las estrategias de la reproducción social. Buenos Aires: Siglo XXI.

Costa, P.R.N., 2012. A elite empresarial e as instituições democráticas: cultura política, confiança e padrões de ação política. Opinião Pública, 18, pp.452-469. DOI: 10.1590/s0104-62762012000200009

,2014. Elite empresarial e elite econômica: o estudo dos empresarios. Revista de Sociologia e Política,22(52), pp.47-57. DOI: $10.1590 / 1678-987314225204$

Costa, P.R.N.; Costa, L.D. \& Nunes, W., 2014. Os senadores-empresários: recrutamento, carreira e partidos políticos dos empresários no Senado brasileiro (1986-2010). Revista Brasileira de Ciência Política, 14, pp.227-253. DOI: 10.1590/0103-335220141409

Crouch, C., 2004. Posdemocracia. Madrid: Taurus. 2011. The Strange Non-Death of Neo-Liberalism. London: John Wiley \& Sons. 
Diniz, E. \& Boschi, R., 2007. A difícil rota do desenvolvimento. Empresários e a Agenda pós-neoliberal. Rio de Janeiro: Humanitas-Iuperj.

,2000. Globalização, herança corporativa e a representação dos interesses empresariais: novas configurações no cenário pós-reformas. In R. Boschi; E. Diniz \& F. Santos, eds. Elites políticas e econômicas no Brasil Contemporâneo. São Paulo, Fundação Konrad Adenauer.

Donatello, L., 2013. Las élites empresariales argentinas, su socialización política y un intento de esbozo comparativo con Brasil. Ponto de Vista, 4, pp.1-21.

, 2014. Elites econômicas e elites políticas frente à democracia: as fontes da debilidade institucional argentina em comparação com o Brasil". In R. Boschi \& S. Bustelo, eds. Brasil e Argentina: políticas e trajetórias de desenvolvimento. Rio de Janeiro: INCT/PPED/E-Papers.

Fraboulet, D., 2010. Les permanents patronaux. In J.E. Daumas, ed. Dictionnaire historique des patrons français. Paris: Flammarion.

Freston, P., 1993. Protestantismo e politica no Brasil: da constituinte ao impeachment. Tese de Doutorado. Campinas: Universidade Estadual de Campinas.

Gaitan, F. \& Boschi, R., 2009. Legados, política y consenso desarrollista. Nueva Sociedad, 224, pp.33-36.

Gaxie, D., 2004. La democracia representativa. Santiago de Chile: Ediciones LOM.

Giddens, A., 1994. Vivir en una sociedad postradicional. In U. Beck; A. Giddens \& S. Lash, eds. Modernización reflexiva. Política, tradición y estética en el orden social moderno. Madrid: Alianza.

Gros, D., 2004. Institutos liberais, neoliberalismo e políticas públicas na Nova República. Revista Brasileira de Ciências Sociais, 19(54), pp.143-159. DOI: 10.1590/s0102-69092004000100009

Heredia, M., 2005. La sociología en las alturas. Aproximaciones al estudio de las clases/elites dominantes en la Argentina. Apuntes de Investigación del CECYP, 10, pp.103-126.

Hervieu-Leger, D., 1993. Religión pour mémoire. París: CERF.

Kliksberg, B., 2010. Las fallas en el gobierno corporativo. Un tema clave en la crisis económica mundial. Revista del CLAD Reforma y Democracia, 47, pp.43-88.

Mallimaci, F., 2015. El mito de la Argentina Laica. Catolicismo, política y Estado. Buenos Aires: Capital Intelectual.

Martins Rodrigues, L., 2009. Partidos, ideologia e composição social: um estudo das bancadas partidárias na Câmara dos deputados. Rio de Janeiro: Centro Edelstein de Pesquisas Sociais.

Martuccelli, D., 2010. ¿Existen individuos en el Sur? Santiago de Chile: Ediciones LOM.

Michels, R., 2008. Los partidos políticos. Un estudio sociológico de las tendencias oligárquicas de la democracia moderna. Buenos Aires: Amorrortu Editores.

Neri, M., 2011. Novo mapa das religiões. Rio de Janeiro: FGV.

Offerle, M., 2004. Los partidos políticos. Santiago de Chile: Ediciones LOM.

Parkin, F., 1978. Orden político y desigualdades de clase. Estratificación social de las sociedadescapitalista y comunista. Madrid: Editorial Debate.

Scott, J., 2014. The Social Process of Lobbying: Cooperation or Collusion? London: Routledge.

Schmitter, P.; Streeck, W. \& Lembruch, G., 1992. Neocorporativismo. Más allá del Estado y del Mercado. México: Alianza Editorial.

Teixeira dos Santos, C. \& Emerick Seabra, J., 2009. Participação feminina no Congresso: Brasil vs. Argentina. Boletim sobre a participação feminina no Congresso, 4. NECON/IUPERJ.

Tissot, S.; Gaubert, C. \& Lechien, M.-H., 2004. Reconversions militantes. Limoges: PULIM.

Vommaro, G.; Morresi, S. \& Bellotti, A., 2015. Mundo Pro. Anatomía de un partidofabricado para ganar. Buenos Aires: Planeta.

Weber, M., 1984. La política como vocación. In ___. El político y el científico. Madrid: Alianza Editorial.

Zabludovsky Kuper, G. 2013. El concepto de individualización en la sociología clásica y contemporánea”. Política y cultura, 39, pp.229-248.

\section{Otras fuentes}

Élites, 2015. Base de datos. Observatorio de Élites Parlamentares en América Latina. Disponible en: http://americo.usal.es/oir/elites/bases_de_datos.htm. Accedido en: 26 ago. 2017.

PELA, 2004. Estudio 51: Argentina. Encuesta a diputados argentinos 2004-2007. Salamanca: Universidad de Salamanca. 2005. Estudio 55: Brasil. Encuesta a diputados brasileños 2002-2006. Salamanca: Universidad de Salamanca. 2008. Estudio 67: Argentina. Encuesta a diputados Argentinos 2007-2011. Salamanca: Universidad de Salamanca. ,2010a. Estudio 73: Argentina. Encuesta a diputados argentinos 2004-2007. Salamanca: Universidad de Salamanca. 2010b. Estudio 75: Brasil. Encuesta a diputados Brasileños 2007-2011. Salamanca: Universidad de Salamanca. 
Deputies and Bussiness World Lobbying in Argentina and Brazil: The Emergence of a Specialist's Category

Abstract

This article proposes to describe different characteristics from deputies in Argentina and Brasil who are, at the same time, representants of business world. To work this, we use the tools bringing by Salamanca University program of Parliamentarian Elites in Latin America. This work is developed under direction of Manuel Alcántara Saéz from 1994. The results show us the emergence of a new category of specialist in representation of interest. This phenomenon is possible thanks to opportunities open by democracy in both cases, more than sociologic characteristics. The essay tries to discuss theories that emphasizes the emergence of new politics linked with globalization process.

KEYWORDS: legislators; bussiness world deputies; Argentina; Brazil; democracy.

This is an Open Access article distributed under the terms of the Creative Commons Attribution Non-Commercial License which permits unrestricted non-commercial use, distribution, and reproduction in any medium provided the original work is properly cited. 